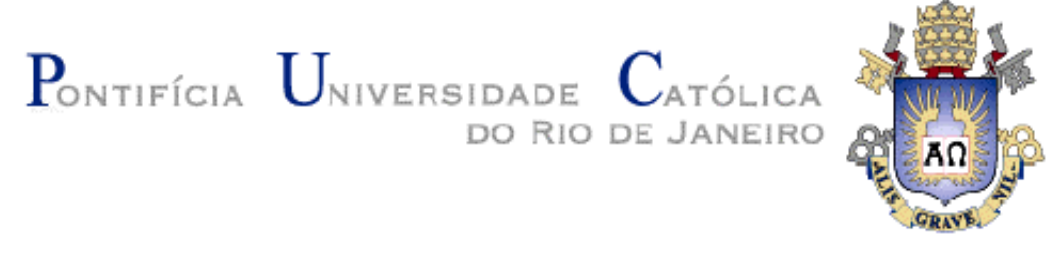

Jomar Rolland Braga Neto

\title{
A Influência do Boca a Boca Online na Decisão de Compra do Consumidor
}

Dissertação de Mestrado

Dissertação apresentada ao Programa de Pósgraduação em Administração de Empresas da PUCRio como requisito parcial para obtenção do título de Mestre em Administração de Empresas.

Orientador: Prof. Paulo Cesar de Mendonça Motta 


\section{Pontifícia Universidade $\mathrm{C}_{\text {atólica }}$

Jomar Rolland Braga Neto

\section{A Influência do Boca a Boca Online na Decisão de Compra do Consumidor}

Dissertação apresentada como requisito parcial para obtenção do grau de Mestre pelo Programa de Pósgraduação em Administração de Empresas da PUCRio. Aprovada pela Comissão Examinadora abaixo assinada.

Prof. Paulo Cesar de Mendonça Motta

Orientador

Departamento de Administração - PUC-Rio

Prof. Luis Fernando Hor-Meyll Alvares

Departamento de Administração - PUC-Rio

Profa. Mônica Zaidan Gomes Rossi

FACC - UFRJ

Prof. Nizar Messari

Vice-Decano de Pós-Graduação do CCS

Rio de Janeiro, 26 de junho de 2009 
Todos os direitos reservados. É proibida a reprodução total ou parcial do trabalho sem autorização da universidade, do autor e do orientador.

Jomar Rolland Braga Neto

Ficha Catalográfica

Braga Neto, Jomar Rolland

A influência do boca a boca online na decisão de compra do consumidor / Jomar Rolland Braga Neto ; orientador: Paulo Cesar de Mendonça Motta. $-2009$.

89 f. : il. (col.) ; $30 \mathrm{~cm}$

Dissertação (Mestrado em Administração)Pontifícia Universidade Católica do Rio de Janeiro, Rio de Janeiro, 2009.

Inclui bibliografia

1. Administração - Teses. 2. Comportamento do consumidor. 3. Boca a boca online. 4. Processo de decisão de compra. I. Motta, Paulo Cesar de Mendonça. II. Pontifícia Universidade Católica do Rio de Janeiro. Departamento de Administração. III. Título. 


\section{Agradecimentos}

Agradeço a todos que me ajudaram nessa caminhada, tanto aos que caminharam comigo durante um tempo quanto aos que deram seu incentivo através de palavras encorajadoras. 


\section{Resumo}

Neto, Jomar Rolland Braga; Motta, Paulo Cesar de Mendonça. A Influência do Boca a Boca Online na Decisão de Compra do Consumidor. Rio de Janeiro, 2009. 89p. Dissertação de Mestrado - Departamento de Administração, Pontifícia Universidade Católica do Rio de Janeiro.

$\mathrm{O}$ crescimento dos acessos a Internet, o avanço das comunidades online e de outras formas de se relacionar virtualmente só tem aumentado no Brasil fazendo com que a rede de computadores faça parte de nossa rotina e também de nossa comunicação diária. A propaganda boca a boca sempre influenciou os consumidores desde que o comércio existiu. Perguntar a conhecidos sobre um produto sempre foi uma opção de receber boas indicações sobre compras. Com a criação da Internet, surgiu o boca a boca online (eWOM), que mudou um pouco essa dinâmica, agora apesar do consumidor não conhecer as pessoas que deixam seus comentários online este confia, mesmo assim, nas suas recomendações. Neste estudo analisam-se os vários tipos de canais de comunicação do boca a boca na Internet de maneira a procurar medir a confiança do consumidor eWOM. Usando de método similar procurou-se avaliar como os comportamentos de socialização e o desejo de ajudar os outros influencia ou não na produção de comentários no mundo virtual. O levantamento de dados para esta avaliação foi feito através de um questionário online respondidos por usuários da Internet. Com estes dados foi possível analisar a frequiência de contato com o eWOM e o quanto a confiança nele influência no comportamento de compra dos consumidores.

\section{Palavras-chave}

Comportamento do consumidor; boca a boca online; processo de decisão de compra. 


\section{Abstract}

Neto, Jomar Rolland Braga; Motta, Paulo Cesar de Mendonça (Advisor). The Influence of the Electronic Word of Mouth Online on the Consumer Purchase Decision Rio de Janeiro, 2009. 89p. MSc. Dissertation - Departamento de Administração, Pontifícia Universidade Católica do Rio de Janeiro.

Internet access is on the increase, online communities are developing at a high rate and other forms of virtual relationship are growing in Brazil, making the computer web a part of our daily routine and communication. The word-of-mouth as a form of advertisement has always influenced the consumers since the origins of commerce. Asking acquaintances about a product has invariably been a good option to receive good tips on shopping. With the creation of the Internet, the online word-of-mouth (eWOM) came along, changing this dynamics a little bit. Nowadays, despite not knowing who posts an online feedback, the consumer trusts it. In this study several types of online word of mouth communication channels were analyzed in search for a way to measure consumer's trust in the eWOM. Using a similar method, socialization and the desire to help others were measured in order to know whether this behavior influences the production of online feedback. The data gathering for this evaluation was carried out through an online questionnaire, answered by Internet users. This data made it possible to analyze the frequency of eWOM exposition and how trusting in it influences the consumer's shopping behaviour.

\section{Keywords}

Consumer behavior; eletronic word-of-mouth; consumer decision process 


\section{Sumário}

1. Introdução 11

1.1. Objetivo Principal 13

1.2. Objetivos Secundários 13

1.3. Delimitação do Estudo 13

2. Referencial Teórico 15

2.1. Processos Decisórios do Consumidor 15

2.1.1. Reconhecimento do Problema ou Necessidade 16

2.1.2. Busca de Informações $\quad 17$

2.1.3. Avaliação de Alternativas Pré-Compra 19

2.1.4. Escolha ou Compra 21

2.1.5. Consumo 23

2.1.6. Avaliação Pós-Consumo 25

2.1.7. Descarte 27

2.2. Grupos de Referência 28

2.3. Líderes de Opinião 31

2.4. Teorias do Fluxo de Comunicação 33

2.5. Teoria dos Laços Fortes e Fracos 34

2.6. WOM na Internet ou Word-of-Mouth ou eWOM 36

2.7. Grupos de Referência na Internet 38

2.8. Líderes de Opinião na Internet 48

2.9. Hipóteses $\quad 50$

3. Método 52

3.1. Entrevistas Iniciais $\quad 52$

3.2. Questionário 53

3.3. Testes Realizados $\quad 57$

3.4. Limitações do Método 60

4. Resultados 61

4.1. Perfil da Amostra 61

4.2. Freqüência de Exposição ao eWOM 62

4.3. Busca Online 66

4.4. Sociabilidade Online 67

4.5. Contribuição Online 69

4.6. Confiança no eWOM 70

4.7. Comparativo de Diferença por Faixas Etárias e Sexo 74

5. Considerações Finais 77

5.1. Reflexões sobre os Resultados 77

5.2. Implicações Acadêmicas 78

5.3. Implicações Gerencias $\quad 80$

6. Referências Bibliográficas 82 


\section{Lista de figuras}

Figura 1 - Modelo de Processo Decisório

Figura 2 - Reconhecimento de Problema: Mudanças do Estado Real e Desejado

Figura 3 - Busca de Informações

Figura 4 - Avaliando Alternativas

Figura 5 - Modelo de Satisfação/Insatisfação do Consumidor

Figura 6 - Teoria do Fluxo de Duas Etapas

Figura 7 - Teoria de Fluxo Multicanal da Comunicação 


\section{Lista de tabelas}

Tabela 1 - Hierarquia de Efeitos 20

Tabela 2 - Influência e Poder Relacionado 31

Tabela 3 - Tipos de Influenciadores do Consumidores 33

Tabela 4 - O Surgimento das Comunidades Online 40

Tabela 5 - Classificação de Comunidades 41

Tabela 6 - Comunidades Virtuais $\quad 45$

Tabela 7 - Sites mais Acessados no Mundo 46

Tabela 8 - Perguntas do Questionário e Variáveis Geradas 54

Tabela 9 - Resumo das Escalas Usadas na Pesquisa 55

Tabela 10 - Quadro de Hipóteses $\quad 58$

Tabela 11 - Freqüência de Idade da Amostra 62

Tabela 12 - Teste t Perguntas 01 a 05

Tabela 13 - Perguntas 01 a $05 \quad 64$

Tabela 14 - Quadro Resumo Testes t 67

Tabela 15 - Quadro Resumo de Regressões 67

Tabela 16 - Freqüência das Componentes da Sociabilidade

Tabela 17 - Freqüência das Componentes da Contribuição Online 70

Tabela 18 - Comparativos Idade e Sexo 
"Nossa maior glória não é nunca haver caído, e sim ter levantado depois de cada queda."

(Confúcio. 551 a.C. a 479 a.C) 